\title{
Geoinformatics in mangrove monitoring: damage and recovery after the 2004 Indian Ocean tsunami in Phang Nga, Thailand
}

\author{
D. Kamthonkiat ${ }^{1}$, C. Rodfai ${ }^{2}$, A. Saiwanrungkul ${ }^{2}$, S. Koshimura ${ }^{3}$, and M. Matsuoka ${ }^{4}$ \\ ${ }^{1}$ Department of Geography, Faculty of Liberal Arts, Thammasat University Thailand, Thailand \\ ${ }^{2}$ Mangrove Administrative Division 2, Department of Marine and Coastal Resources, Ministry of Natural Resources and \\ Environment, Thailand \\ ${ }^{3}$ Disaster Control Research Center, Graduate School of Engineering, Tohoku University Japan, Japan \\ ${ }^{4}$ GEO Grid Research Group, Information Technology Research Institute, National Institute of Advanced Industrial Science \\ and Technology (AIST), Japan
}

Received: 21 December 2010 - Revised: 9 May 2011 - Accepted: 9 June 2011 - Published: 6 July 2011

\begin{abstract}
In the aftermath of the 2004 Indian Ocean Tsunami, it has been proven that mangrove ecosystems provide protection against coastal disasters by acting as bioshields. Satellite data have been effectively used to detect, assess, and monitor the changes in mangroves during the pre- and post- tsunami periods. However, not much information regarding mangrove restoration or reforestation is available. Rather than undertaking time-consuming fieldwork, this study proposed using geoinformatic technologies such as Remote Sensing (RS), Geographic Information System (GIS), and Global Positioning System (GPS) to monitor the mangrove recovery. The analysis focused only on the tsunami-impacted mangrove areas along the western coast of the Tai Muang, Takuapa and Khuraburi Districts of Phang Nga Province, southern region of Thailand. The results consisted of 2 parts, first: the supervised classification of main land uses, namely forest, mangrove, agricultural land, builtup area, bare soil, water body, and miscellaneous covers in ASTER images, was conducted using the maximum likelihood method with higher than $75 \%$ for overall accuracy. Once the confusion between classes was improved in postprocessing, the accuracy of mangrove class was greater than $85 \%$ for all dates. The results showed that the mangrove area in 2005 was reduced by approximately $5 \%$ (1054.5 ha) from 2003 due to the impact of the 2004 Indian Ocean Tsunami. Although the recovery program (replacing the same species of dead mangrove trees, mainly the Rhizophora apiculata B1 and Rhizophora mucronata Poir, in situ) had started by mid2005 , the areas gradually decreased to approximately $7-8 \%$ in 2006 and 2010 compared with the reference year of 2003. Second, the recovery trend was observed in the Normalized
\end{abstract}

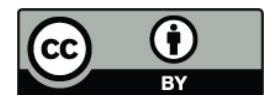

Correspondence to: D. Kamthonkiat (dawan@tu.ac.th)
Difference Vegetation Index (NDVI) fluctuation curve and the supporting field survey data. The recovery patterns were summarized into 2 categories: (i) gradually recovery, and (ii) fluctuating recovery. The gradually recovery category that implied the homogeneous pattern or uniform reforestation was observed in the seriously damaged area where most of the mangrove trees were swept away during the tsunami. This pattern covered approximately $50.35 \%$ of the total reforested area. The NDVI time series of the uniform or homogeneous reforested mangrove at the sampled plots has gradually increased after 2005 . The fluctuating recovery category that implied the heterogeneous pattern or non-uniform reforestation was observed in partially damaged areas where some of the mangrove trees were swept away and broken but still some trees were remained in the area. The heterogeneous patterns covered approximately $49.65 \%$ of the total reforested area.

\section{Introduction}

On 26 December 2004, two earthquakes with magnitudes of 9.3 and 7.3 on the Richter scale induced tsunamis that hit Thailand and many countries along the Andaman Coast, and some African countries. The death toll from the 2004 tsunami was reported to be nearly 230000 . In the south of Thailand, the casualties (including unidentified bodies) numbered 5395 in the affected provinces along the Andaman Coast, namely Phang Nga, Phuket, Satun, Krabi, Ranong, and Trang. Nearly half of the casualties were foreign citizens from 36 countries. The highest death toll $(78.3 \%$ of the 5395 was reported from Phang Nga. Beyond the heavy toll on human lives, the giant wave also caused enormous damage to ecosystems such as mangroves, coral reefs, sand dunes, groundwater, and forests and to human settlements

Published by Copernicus Publications on behalf of the European Geosciences Union. 
and agricultural lands along the coast of Phang Nga Province (ONEP, 2006; UNEP, 2005; World Bank/UNDP, 2005).

After the disaster, geoinformatics technologies such as Remote Sensing (RS), the Geographic Information System (GIS), and the Global Positioning System (GPS) as well as field surveys were effectively used to map the locations damaged by the tsunami, land cover changes, and the later recovery status. RS provided strong support to the preliminary damage assessment soon after the 2004 Indian Ocean Tsunami at various spatial resolutions including data obtained at less than a meter's spatial resolution. These data included high-resolution satellite imagery obtained from DigitalGlobe, low-resolution imagery obtained from the National Oceanic and Atmospheric Administration (NOAA), and intermediate-resolution data obtained from the Moderate Resolution Imaging Spectroradiometer (MODIS) instrument onboard the TERRA and AQUA satellites. In assessing the damages wrought by the tsunami in Phang Nga, a large number of Thai and international agencies and research teams initiated rapid assessments of the impacts of the 2004 Tsunami in the affected provinces of Thailand. Such effort was aimed at collecting information on tsunami inundation, building damage characteristics, ground and foundation failures, and eyewitnesses and survivor accounts. The locations of damaged areas were recorded using GPS as point features and linked with GIS (Sirikulchayanon et al., 2008; Siripong, 2006; Thanawood et al., 2006; Tsuji et al., 2006; DMCR, 2005; Yamazaki et al., 2005). It was noted in these reports that the run-up height and severity of impact on the damaged areas varied due to differences in landforms, slope and elevation, and the presence of natural barriers such as coral reefs and mangroves. The reports also indicated that the number of housing settlements that were damaged and left a number of homeless victims was significant in areas where mangroves and beach forests did not exist. Subsequently, the protection against coastal disasters or bioshield action of mangroves was demonstrated and reported as an important service of mangroves and other coastal forests in protecting the communities behind them from the surge of tsunamis (Tanaka, 2009; Barbier, 2008; Chatenoux and Peduzzi, 2007; Forbes and Broadhead, 2007; UNEP-WCMC, 2006; Kashio, 2005; Kathiresan and Rajendran, 2005). Thus, mangrove monitoring in the tsunami-impacted province became a crucial goal of governmental agencies of Thailand (in particular, the Department of Marine and Coastal Resources (DMCR) of the Ministry of Natural Resources and Environment (MONRE)).

However, field observations used to update the areas and conditions of the replanted mangrove plots were limited due to time and financial limitations. Therefore, our study attempted to use geoinformatic technologies such as GIS, multi-temporal RS, and GPS as well as field surveys to specifically: (i) assess the mangrove areas affected by the 2004 tsunami and update the extent of the mangrove areas in Phang Nga Province, Southern Thailand; and (ii) study the reforestation pattern of the mangroves using multi-temporal
RS. This effort was aimed at assessing up-to-date information in these areas regarding the status of mangroves in the plots replanted for conservation and reforestation purposes.

\section{Study area/site description}

Phang Nga, which is located in the southern region of Thailand, consists of hilly and mountainous areas that range from the north to the south, and along the Andaman coast (approximately $240 \mathrm{~km}$ ). The physical characteristics of the coastal area in Phang Nga Province, which include an estuary and a narrow gulf, caused the water mass of the 2004 Indian Ocean Tsunami to flow through a region of shallow bathometry and consequently to increase in height, resulting in severe damage that seriously impacted human lives and ecosystems such as mangroves, coral reefs, sand dunes, groundwater, and forests. In this study, our analysis was framed by the most impacted mangrove areas along the western coast of the Tai Muang, Takuapa, and Khuraburi Districts of Phang Nga, as shown in Fig. 1.

The DMCR (2006) reported that mangrove forests in Phang Nga covered 51100 ha in 1961, but this area decreased to 30442 ha by 1996 , mainly due to the growth of tin mining, the construction of fishing port facilities and shrimp farms, and urban development related to tourism. Under the government rehabilitation plan afterward, permits for mining activities were cancelled in early 2004 , and the mangrove forests have been rehabilitated and now cover an area of 44301.58 ha.

After the Tsunami on 26 December 2004, the areas of the affected provinces that were badly impacted (Phang Nga, Phuket, Satun, Krabi, Ranong, and Trang) were surveyed by many agencies, but a detailed assessment of the damaged mangrove areas and the rehabilitation process was conducted at the beginning of 2005 by DMCR of MONRE and its local collaborators, such as the Institute for Research and Development of Marine and Coastal Resources (Phuket Marine Biological Center) and the Mangrove Forest Research and Development Stations along the Andaman Coast. The direct force of the tsunami tore the mangrove leaves and branches, and, in some places, whole trees were uprooted. The silt deposited by the wave clogged the pores of the aerial roots of the mangroves, and the soil salinity and upstream flows of freshwater adversely affected the growth of the mangroves. Other items carried by the tsunami, such as fishing boats and construction materials from the beach, also broke and knocked down the mangrove trees. The local Mangrove Resource Administration and Management Division of DMCR incorporated with DDPM and other government agencies and nonprofit volunteers cleared broken branches and uprooted mangrove trees, and removed artificial debris and dead victims. In Phang Nga, the area of mangrove forests damaged during the 2004 tsunami was reported to be $305.92 \mathrm{ha}(1912 \mathrm{rai}, 1 \mathrm{ha}=6.25 \mathrm{rai})$, and over 


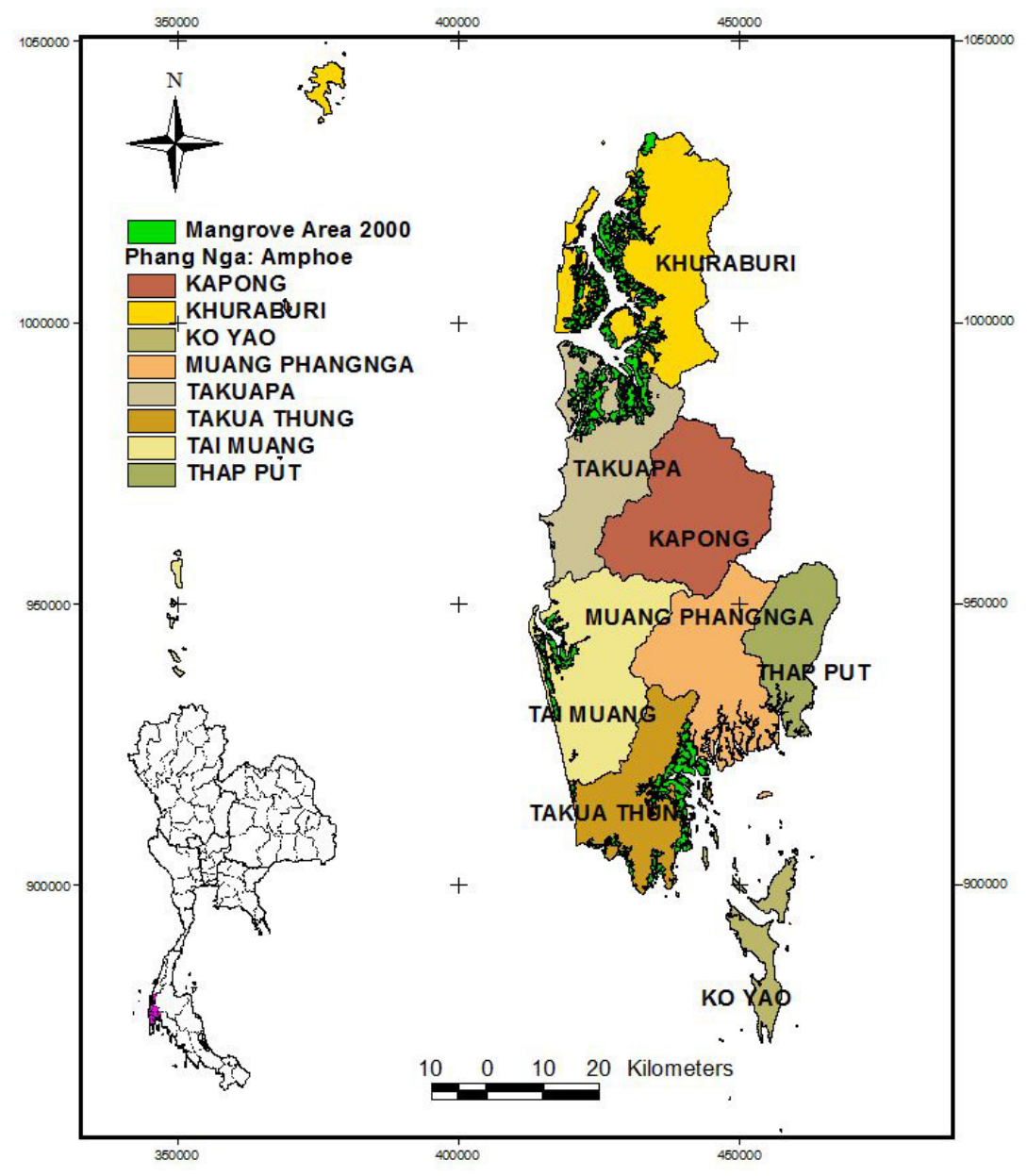

Fig. 1. The study area.

304 ha (1900 rai) was recorded, especially in coastal areas where the tsunami had the greatest physical impact (Rodfai, 2005). Since then, a program to conserve and rehabilitate mangrove forests in the affected areas has been established by MONRE, in which activities and campaigns have been promoted by encouraging the people, government, and private sectors to participate in mangrove re-planting (in particular, during the last quarter of 2005).

A number of mangrove seedlings were prepared for the reforestation project by the local offices of DMCR and its offices outside the tsunami-affected areas. The reforestation project in Phang Nga covered approximately 309 ha, a little more than the damaged 304 ha. Thirty-four plots were planted with Rhizophora apiculata $\mathrm{Bl}$ and Rhizophora mucronata Poir, of which approximately 114 ha (12 tree plots) were in Takuapa, 139 ha (14 tree plots) in Khuraburi, and 56 ha ( 8 tree plots) in Tai Muang District. The size of the plots varied depending on the extent of damage at each location. The extent and locations of the reforested tree plots in the 3 districts were recorded using GPS and GIS. Mangrove tree seedlings were planted at spacing of $1.5 \times 1.5 \mathrm{~m}$, and then the density of the trees was equally controlled in the reforested plots. A few years later, the overall growth performance parameters - including height, trunk diameter, and the number of survived trees within each $10 \times 10 \mathrm{~m}$ plot - were randomly monitored. The dead mangrove trees in the sampled plots were replaced with new seedlings (Rodfai, 2008). Rather than undertaking time-consuming field-works, this study proposed using geoinformatic technologies such as RS, GIS, and GPS to monitor the mangrove recovery. The analysis focused only on the tsunami-impacted mangrove areas along the western coast of the Tai Muang, Takuapa, and Khuraburi Districts of Phang Nga.

\section{Materials and methods}

The required materials consisted of digital maps, satellite images, and field survey data as detailed in Sect. 3.1. The framework of this study is explained in Sect. 3.2. 
Table 1. Satellite images used in this study.

\begin{tabular}{lll}
\hline $\begin{array}{l}\text { Satellite Platform } \\
\text { (No. of scene) }\end{array}$ & $\begin{array}{l}\text { Wavelength and Spatial } \\
\text { Resolution } \\
\text { (meters) }\end{array}$ & $\begin{array}{l}\text { Acquisition } \\
\text { Date }\end{array}$ \\
\hline ASTER (12 scenes) & VNIR, 15 m & 7 Mar 2003 \\
& VNIR, 15 m & 8 Feb, 2005 \\
& VNIR, 15 m & 26 Jan 2006 \\
& VNIR, 15 m & 6 Feb 2010 \\
\hline
\end{tabular}

\subsection{Materials}

\subsubsection{Satellite imagery}

Multi-temporal analysis was performed using the high3performance optical sensor ASTER (Advanced Spaceborne Thermal Emission and Reflection radiometer) from the GEO Grid of the National Institute of Advanced Industrial Science and Technology (AIST) of Japan. ASTER uses 14 bands ranging from the visible to the thermal infrared regions, 4 bands in the visible and near infrared regions (VNIR) with $15 \mathrm{~m}$ spatial resolution, 6 bands in the short-wave infrared region (SWIR) with $30 \mathrm{~m}$ spatial resolution, and 5 bands in the thermal infrared region (TIR) with $90 \mathrm{~m}$ spatial resolution. The satellite images used in this study are shown in Table 1.

Based on the different sizes of the ASTER images used in this study (Fig. 2), these images were resized to the similar size of the smallest image of 2003. The analysis of the land covers and mangrove extent in the study area was therefore focused on a fraction of the districts, specifically in the western part of the Tai Muang, Takuapa and Khuraburi Districts, and did not cover all of the mangrove areas in the districts.

Optical and microwave remote sensing technologies are increasingly recognized as significant for the assessment of disaster-damaged areas, especially in areas of Thailand that were affected by the 2004 Indian Ocean Tsunami (Roemer et al., 2010; Koshimura et al., 2009; Kouchi and Yamazaki, 2007; Vu et al., 2007; Jean-Baptiste and Jensen, 2006; Polngam, 2005). According to the literature, vegetation, soil, and water indices can be used to conduct change detection analysis and classify tsunami-impacted areas. The red (RED, 0.6-0.7 $\mu \mathrm{m}$ ), near-infrared (NIR, 0.7-1.3 $\mu \mathrm{m}$ ) and short-wave infrared (SWIR, 1.3-2.5 $\mu \mathrm{m}$ ) regions of the electronic spectrum have been found to be useful for the detection of plant water content as the soil and vegetation watersensitive band. The red band senses only one leaf layer because of the strong chlorophyll absorption, whereas the NIR can sense approximately eight leaf layers. Water has high absorption in the SWIR but it does not absorb in the NIR. The Normalized Difference Vegetation Index (NDVI) is calculated as $(\rho \mathrm{NIR}-\rho \mathrm{RED})$ and $(\rho \mathrm{NIR}+\rho \mathrm{RED})$, where

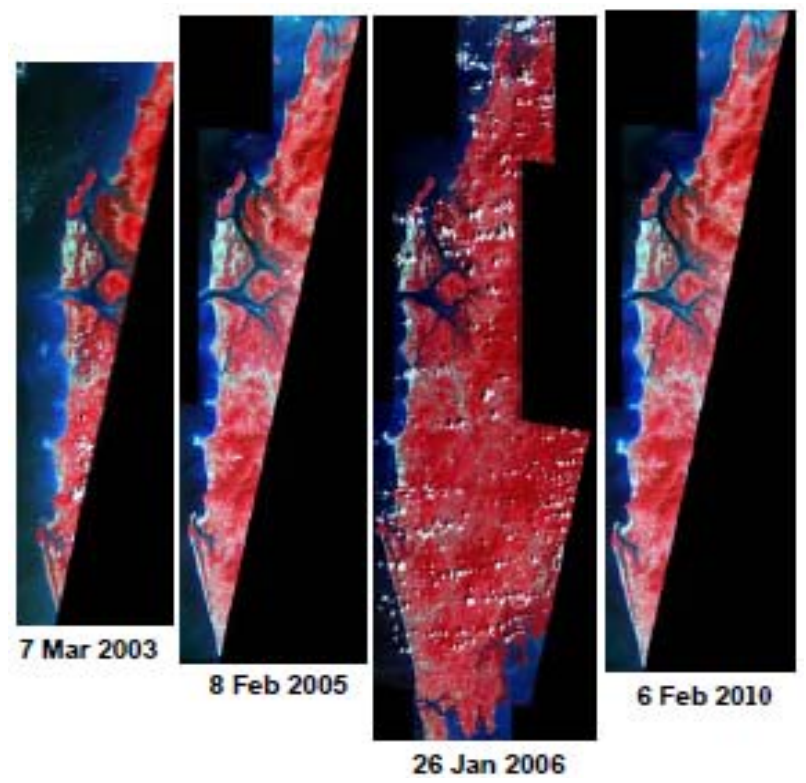

Fig. 2. Preview of the images used in the analysis.

$\rho$ RED is the brightness (or radiance in reflectance units) of the red band, and $\rho$ NIR is the brightness of the nearinfrared band (see also Eq. 1). Following the same rational as with NDVI, the Normalised Difference Soil Index (NDSI) and the Normalised Difference Water Index (NDWI) present as $(\rho \mathrm{SWIR}-\rho \mathrm{NIR}) /(\rho \mathrm{SWIR}+\rho \mathrm{NIR})$ and $(\rho \mathrm{RED}-$ $\rho$ SWIR $) /(\rho$ RED $+\rho$ SWIR $)$, respectively. These indices are calculated in addition to the NDVI to better understand the relationship between vegetation vigor and moisture availability.

Many studies have demonstrated the high capability of these indicators to identify changes that happen over time, especially for degraded vegetation. Siripong (2006) studied the effects of the tsunami on six provinces along the western coast using various procedures and classified the satellite data on two scales, namely: the medium-resolution LANDSAT (LAND + Satellite) and the high-resolution IKONOS (commercial earth observation satellite) data. The NDVI was computed based on LANDSAT data using the indicators of the impacts from the 2004 Indian Ocean Tsunami. In the NDVI image, all pixels with a negative difference were grouped into 3 classes, namely: high tsunami impact (NDVI value greater than 0.5), moderate tsunami impact (NDVI value between 0.5 and 0.1 ), and low tsunami impact (NDVI value between 0 and 0.1 ). From the results, it was concluded that Phang Nga was the most damaged province in Thailand and Satun Province was the least damaged. Moreover, highresolution IKONOS satellite data were used to detect the details of changes in the coastlines at specific areas.

Kouchi and Yamazaki (2007) presented the results of their analysis on the thresholds of the indices, which indicated the surface characteristics of tsunami-affected areas that can be 
observed and detected through land cover changes, using the normalized difference vegetation (NDVI), soil (NDSI), and water (NDWI) indexes computed based on ASTER images of the moderate-resolution imagery sets. The thresholds were derived from two cases: the first for tsunami damage detection was based solely on data acquired after the disaster, and the second was based on the difference in data regarding the indices before and after the tsunami. The analysis showed that the NDVI value decreased in the tsunami-impacted area, whereas the NDSI and NDWI values increased. Furthermore, the thresholds of the indexes used to identify the tsunami-affected areas were determined based on: (i) only the post-event image being used, and (ii) use of both the preevent and post-event images.

Remote sensing studies that examined various indices with reference to specific mangroves have been presented by Jean-Baptiste and Jensen (2006), Blasco et al. (1998), Jansen et al. (1991), and other studies. Jean-Baptiste and Jensen (2006) investigated the use of ASTER data to assess mangroves in the Bocozelle ecosystem in Haiti, where strong correlations between in situ vegetation parameters such as tree height, leaf area index (LAI), and percent canopy closure, and the remote sensing-derived indices obtained from NDVI and the Soil Adjusted Vegetation Index (SAVI) were found (ranging from 0.798 to 0.908 ). Thus, the present study made use of ASTER data to analyze the biophysical condition of the mangroves. NDVI was selected as an index to analyze mangrove recovery using the multi-temporal ASTER data based on the NDVI formula (Jean-Baptiste and Jensen, 2006):

$\mathrm{NDVI}=\frac{\rho_{\text {nir }}-\rho_{\text {red }}}{\rho_{\text {nir }}+\rho_{\text {red }}}$

where

$\rho_{\text {red }}$ : brightness value of the red band in the image

$\rho_{\text {nir }}$ : brightness value of the near infrared band in the image.

Digital image processing techniques such as geometric correction and use of image ratio (NDVI), image classification, and image validation (confusion matrix) were conducted using ENVI 4.6 software.

\subsubsection{Digital maps in GIS format}

The details and source of the GIS data are as follows:

- The topographic map of Phang Nga Province for the year 2000 published at 1:50000 scale by the Royal Thai Survey Department (RTSD) was used as reference data for geometric correction of the satellite images.

- Land-use maps of Phang Nga Province for 2000 and 2007 at 1:50000 and 1:25000 scales, respectively, published by the Land Development Department (LDD) were used for the validation of the classified imagery: ASTER in 2003 and 2006.
- A map of the mangrove reforestation sites of Phang Nga Province in 2005 at 1:50000 scale published by the Mangrove Resources Administration and Management Division No. 2 of DMCR, MONRE, located the 34 plots of reforested mangroves in Phang Nga. Mangrove recovery in these plots was analyzed using multitemporal RS images.

Data management and visualization of the digital maps were carried out using ArcGIS 9.2 software.

\subsubsection{Field data}

Field surveys were conducted in the study area annually from 2006 to 2010. Land uses/land covers in the study area were observed by the research team with the assistance of local staff from the office of Mangrove Resources Administration and Management Division No. 2 of the DMCR of MONRE. Additional field data, such as those regarding the tsunamiimpacted areas, land cover changes in 2005, and the results of the detailed field work on mangrove rehabilitation in Phang Nga were also provided by the office of Mangrove Resources Administration and Management Division No. 2 and other offices under the DMCR.

In the field, handheld GPSs, digital cameras, and measuring tapes were used to record the geographic positions and conditions of the sites visited.

\subsection{Methods}

After preparing the required maps in GIS format, we preprocessed the multi-temporal satellite images and field data collected by our research team and the existing data from various sources at the DMCR of MONRE, including geometric correction using the road maps and co-registration between the images, where the errors inherent in the multi-date images less are than one-half of a pixel. The ASTER images were mosaicked, where 3 scenes from each date covering the study area were combined into one image. Meanwhile, each image was transformed into NDVI format following Eq. (1). The reforested mangrove plots in GIS format were used to compute the multi-temporal NDVI, which was then used to analyze the mangrove recovery. The density of the trees in the reforested plots was determined using the values of NDVI, which ranged from -1 to 1 . Values lower than 0 indicate wet soil (water is at -1 ), 0 represents bare boil and built-up areas, and values between 0 and +1 imply vegetation cover in the area. Cloud masking was conducted using the 2003 and 2006 images, and all images were trimmed to the same size as that of 2003 before classification.

During processing, supervised classification of the seven (7) classes of land cover was emphasized, namely: forest, mangrove, agricultural land, built-up area, bare soil, water body, and miscellaneous cover. The accuracy of the classified images was evaluated post-classification using the reference maps and field data mentioned in Sect. 3.1. The satisfactory 


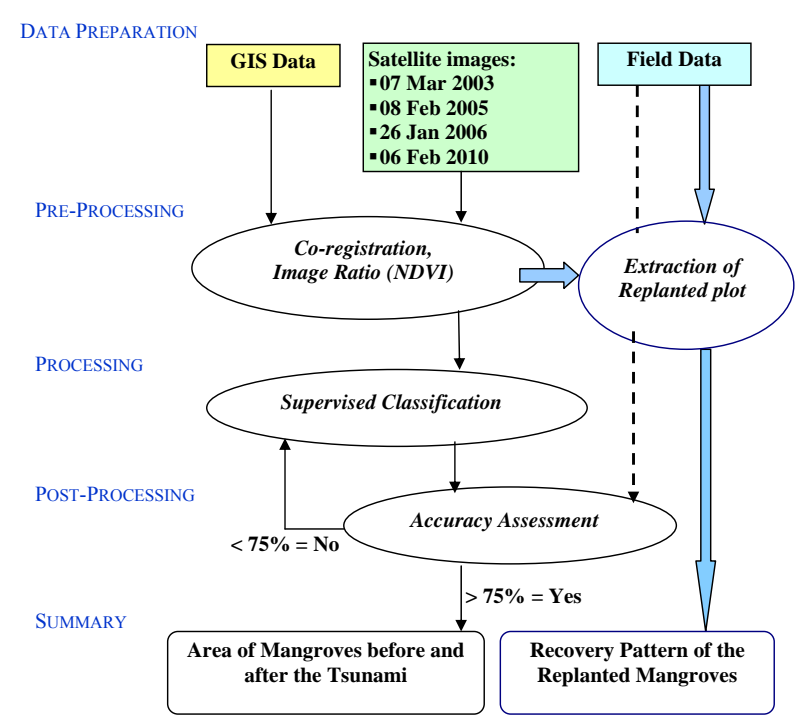

Fig. 3. Framework of the methodology.

overall accuracy in this study was higher than $75 \%$ for all the classified images instead of higher than $80 \%$ because of the images that were affected by cloud cover and atmospheric effects, especially in the images of 2003, 2005, and 2006. Because mangrove was the main target of the study, any misclassification among mangroves, agriculture, and forests was improved based on the reference land uses map and field data. After the improvement, the accuracy of classification as mangroves was greater than $85 \%$ for all dates. Finally, the study yields results in 2 parts corresponding to the objectives of the study. First, the areas of mangrove coverage were summarized for each date and compared to observe changes over time. Second, the recovery pattern of mangrove was observed in the NDVI fluctuation curves and the supporting field survey data. Monitoring of the recovery of the mangroves focused on the reforested plots in the study area. Field surveys were conducted onsite using GPS and digital cameras to check and record the location of the plots and to determine the growth of the mangrove trees with measuring tapes. Figure 3 presents the framework of the above explanation.

\section{Results}

The results consisted of 2 parts: (i) the supervised classification, and (ii) framed mangrove area comparisons between dates. In addition, the NDVI fluctuation was analyzed to group the mangrove recovery patterns in the reforested plots. However, only the sampled plots of each pattern are presented in Sect. 4.2.

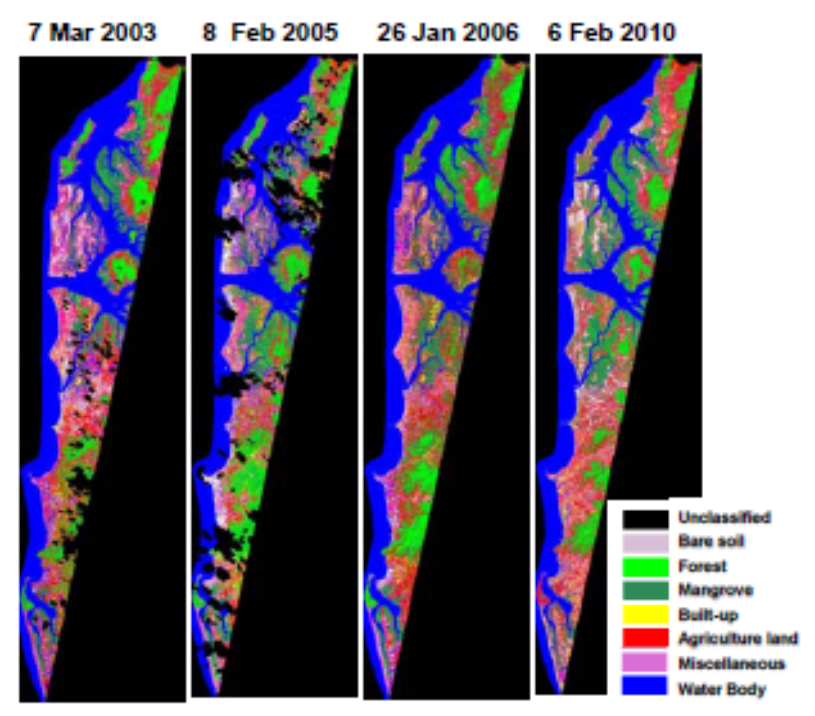

Fig. 4. Images of land use/cover classes.

\subsection{Results of the Supervised Classification}

The land use/land cover was grouped into 7 classes, namely: forest, mangrove, agricultural land, built-up area, bare soil, water body, and miscellaneous cover as shown in Fig. 4. The results were validated using existing maps and field data as presented in Table 2.

For the framed mangrove class, classification of each image was improved using the field data and reference map from LDD and DMCR, resulting in a final accuracy for the mangrove class in all images of greater than $85 \%$. The extracted mangrove area for 2003 was used as a reference image when comparing the areas in images for other years. The mangrove areas of the western parts of 3 districts, Tai Muang, Takuapa, and Khuraburi, are shown in Table 3.

The results showed that the total mangrove area of the three districts in 2003 was 20678 ha or $45.7 \%$ of the total mangrove area in Phang Nga, (44301.58 ha at the beginning of 2004 was referenced as $100 \%$ ). Thus, the results showed that the mangrove area in 2005 was reduced by approximately $5 \%$ (1054.5 ha) from 2003, and most of the changes were due to the impact of the 2004 Indian Ocean Tsunami. Although the Government's recovery program had started by mid-2005, the areas gradually decreased after the reforestation program by approximately $7-8 \%$ in 2006 and 2010 compared with the reference year of 2003. In some locations, some mangroves that had not been swept away or broken by the tsunami were affected by the silt deposited by the tsunami, clogging the pores of their aerial roots. Moreover, soil salinity and the flow of upstream freshwater also affected the growth of the mangroves later, especially in the areas that had been inundated. Therefore, mangroves could be degraded and even die months or years after the tsunami. 
Table 2. Overall accuracy of the classified images.

\begin{tabular}{lll}
\hline Classified Image & Overall Accuracy (\%) & Remarks; confusion between classes \\
\hline 7 Mar 2003 & $84.2 \%$ & - Bare soil and built-up areas \\
\hline 8 Feb 2005 & $77.8 \%$ & $\begin{array}{l}\text { - Forest, mangrove, and agricultural land } \\
\text { - Bare soil and built-up areas }\end{array}$ \\
\hline 26 Jan 2006 & $79.9 \%$ & $\begin{array}{l}\text { - Agricultural land, forest, and mangroves } \\
\text { - Built-up areas and miscellaneous cover types }\end{array}$ \\
\hline 6 Feb 2010 & $81.6 \%$ & - Bare soil, built-up areas, and miscellaneous cover types \\
\hline
\end{tabular}

Table 3. Areas of mangroves in the study area.

\begin{tabular}{lllll}
\hline $\begin{array}{l}\text { Mangrove } \\
\text { Area } \\
\text { (Hectares) }\end{array}$ & 2003 & 2005 & 2006 & 2010 \\
\hline Khuraburi & 12337.18 & 11960.37 & 11794.19 & 11775.85 \\
Takuapa & 5966.93 & 5713.07 & 5519.00 & 5343.10 \\
Tai Muang & 2373.80 & 1949.99 & 1889.42 & 1852.99 \\
\hline Total & $\mathbf{2 0 6 7 7 . 9 1}$ & $\mathbf{1 9 6 2 3 . 4 3}$ & $\mathbf{1 9 2 0 2 . 6 1}$ & $\mathbf{1 8 9 7 1 . 9 4}$ \\
\hline Percent $(\%)$ & $\mathbf{1 0 0 . 0 0}$ & $\mathbf{9 4 . 9 0}$ & $\mathbf{9 2 . 8 7}$ & $\mathbf{9 1 . 7 5}$ \\
\hline
\end{tabular}

The degraded mangrove areas in many locations were reclassified into other land cover classes, i.e., agricultural land and miscellaneous cover. The mangrove area was therefore much reduced in 2005 compared to the area (306 ha) that was reported as tsunami-impacted soon after the event.

In Khuraburi District in 2005, the mangrove area was $97 \%$ of the reference area of 2003 with a decrease of only $1 \%$ in 2006, and the area remained similar in 2010. The mangrove area in Takuapa decreased by almost $5 \%$ after the tsunami in comparison to the reference year of 2003, whereas the areas gradually decreased by a few percent in 2006 and 2010, reducing to $92.5 \%$ and $89.6 \%$, respectively. The mangrove area in the northwestern part of Tai Muang District exhibited the most serious change with an approximately $18 \%$ reduction from the area it had in the reference year of 2003. Even after the recovery period, the area of mangroves in the District indicated a minimal percent decrease in 2006 and remained almost unchanged in 2010. The changes in the areas covered by mangroves per district are presented in Fig. 5.

Although the mangrove areas in the study area had been reforested in 2005, the areas classified as mangroves continued to decrease after 2006. Because the rate of growth and recovery was less than average, the reforestation effort can be considered unsuccessful based on the number of surviving trees, in particular in areas where the topography had changed and the soil quality had been degraded. In some locations, serious erosion had occurred due to the tsunami.

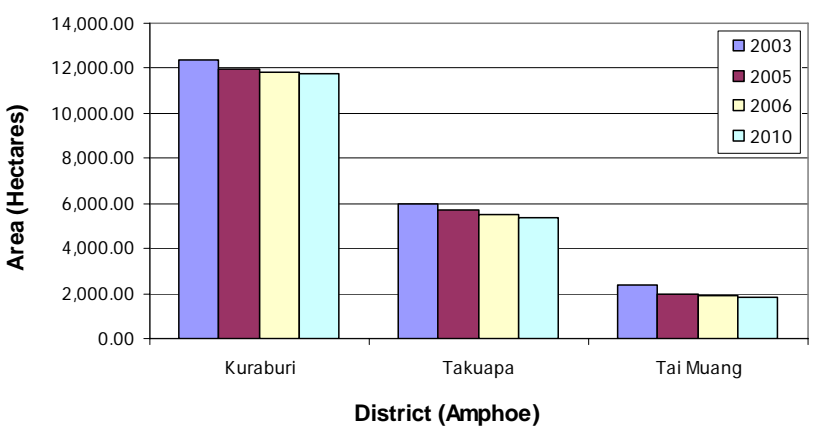

Fig. 5. Changes in mangrove area by district.

Thus, the area covered by mangroves was found to be less than before the tsunami. Some trees were, however, found to be growing in eroded areas with deeper water and stronger waves. After the tsunami, the continued construction of shrimp farms, urban recovery, and tourist related development in the study area may have encroached upon some mangrove areas, explaining the recovery trends of the reforested mangrove in the different locations (see the next subsection). 


\subsection{Trend Analysis of the mangrove recovery in the reforested plots}

Based on the survey results and discussions with the local DMRC staff, the same species of mangrove trees (mainly the Rhizophora apiculata $\mathrm{Bl}$ and Rhizophora mucronata Poir), approximately $1 \mathrm{~m}$ high, were used to replace the dead trees in situ after mid-2005 following the same spacing of $1.5 \times 1.5$ and the same density in $10 \times 10 \mathrm{~m}$ plots. A year later, the mangrove trees within $10 \times 10 \mathrm{~m}$ random plots were counted and measurements of their height, trunk diameter, and leaf area were taken. In Tai Muang, Takuapa, and Khuraburi Districts, the replanted Rhizophora apiculata B1 in the random plots showed an average growth of approximately $28 \mathrm{~cm}$ per year in height and an increase of $3-10 \mathrm{~cm}$ in trunk diameter. Approximately $80 \%$ of the replanted trees survived from 2006 until 2010. For Rhizophora mucronata Poir, the average growth was approximately $30 \mathrm{~cm}$ per year in height and an increase of $3-12 \mathrm{~cm}$ in trunk diameter. The survival rate was approximately $86 \%$. The average height of the mangrove trees grown after the tsunami, however, was lower than the average natural growth rate of $31-40 \mathrm{~cm}$ per year (Rodfai, 2008). Newly planted trees often take some time to establish their roots. Moreover, the degraded soil fertility in the areas that had been inundated also affected the growth of the mangroves.

From such reforestation efforts, an analysis of the NDVI fluctuation curve of all reforested plots was conducted, and the patterns of NDVI fluctuation were observed. The results indicated that the NDVI of the mangroves in the study area ranged from 0.2 to 0.6 rather than the full range from -1 to 1 . Thus, the graphs presented in this study focused only on the range of 0 to 0.6 to gain a better understanding of the trend in NDVI fluctuation. The patterns of NDVI were correlated with the field data and the growth observations recorded by the local staff of DMCR. The recovery trends were summarized into 2 categories that implied the patterns of mangrove reforestation: (i) gradual recovery (homogenous), and (ii) fluctuating (heterogeneous). Moreover, rather than presenting a number of similar NDVI fluctuation graphs, we include only a representative of each pattern in the results.

\subsubsection{Gradual recovery in the homogeneous plots}

Gradual recovery was noted in the severely damaged area where most of the mangrove trees were swept away during the tsunami. Figure 6 depicts the area of mangroves in 2003 in red and the area impacted by the tsunami in 2005 in dark blue and white for the same location. After mangrove trees were uniformly or homogeneously replanted in the same location in the last quarter of 2005 in Takuapa District, the area marked in red increased in 2006 and increased still further in 2010, as shown in Fig. 6 (Note: red represents vegetation or mangroves, white represents bare soil/sand, and blue/dark blue represents water). Since 2005, the height of the man-

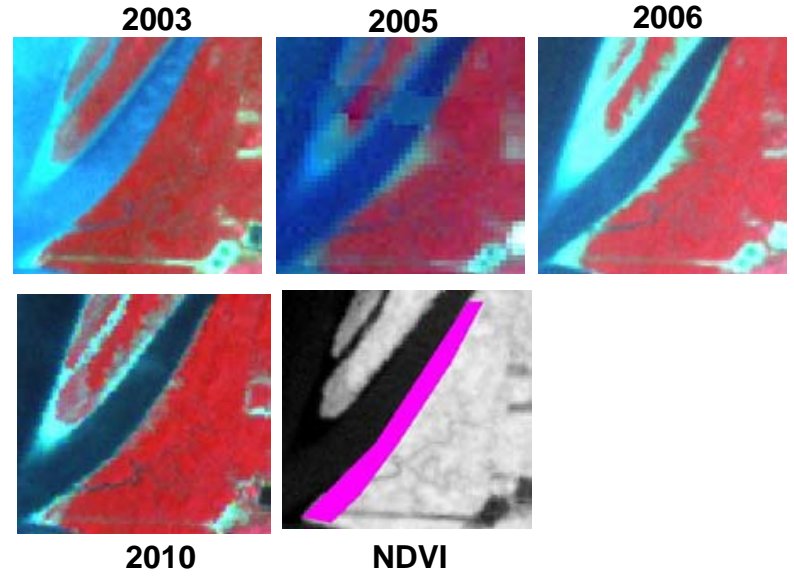

Fig. 6. The gradually recovered mangrove area (homogeneous plot) in Takuapa.

grove trees has gradually increased from 1 to $3 \mathrm{~m}$ (from A, B, C and D, respectively, as presented in Fig. 7).

From such reforestation efforts and gradual recovery, the multi-temporal NDVI of this reforested plot (the magenta area overlaid on NDVI in Fig. 6) was analyzed as shown in Fig. 8. The NDVI of 2005 had strongly decreased compared to the reference value for 2003, as most of the mangrove trees were swept away during the tsunami. After the new mangrove trees were replanted and following gradual recovery, the NDVI increased in 2006 and still further in 2010. The homogeneous or uniform pattern of mangrove replanting covered approximately $50.35 \%$ of the total areas of mangrove reforestation.

Figure 9 presents the updated status of mangroves in Tai Muang (upper) and Kuraburi (lower). The height of mangroves in the gradually recovering areas ranged from 2 to $4 \mathrm{~m}$.

\subsubsection{Fluctuating recovery in the heterogeneous reforested plots}

Fluctuating recovery was observed in the partially damaged areas where some of the mangrove trees were either swept away or broken but remained in the area. Thus, the NDVI of 2005 did not decrease much compared with 2003 (Fig. 10). However, the NDVI in 2006 decreased greatly compared with 2005. This was due to the effect of the tsunami in the affected area, because the trees that were heterogeneous newly planted during the last quarter of 2005 did not grow well due to poor soil quality. The remaining trees were also affected by the silt that had been deposited by the tsunami, clogging the pores of the aerial roots of the mangroves, which eventually became damaged or died. The heterogeneous or nonuniform pattern of mangrove replanting covered approximately $49.65 \%$ of the total areas of mangrove reforestation. 

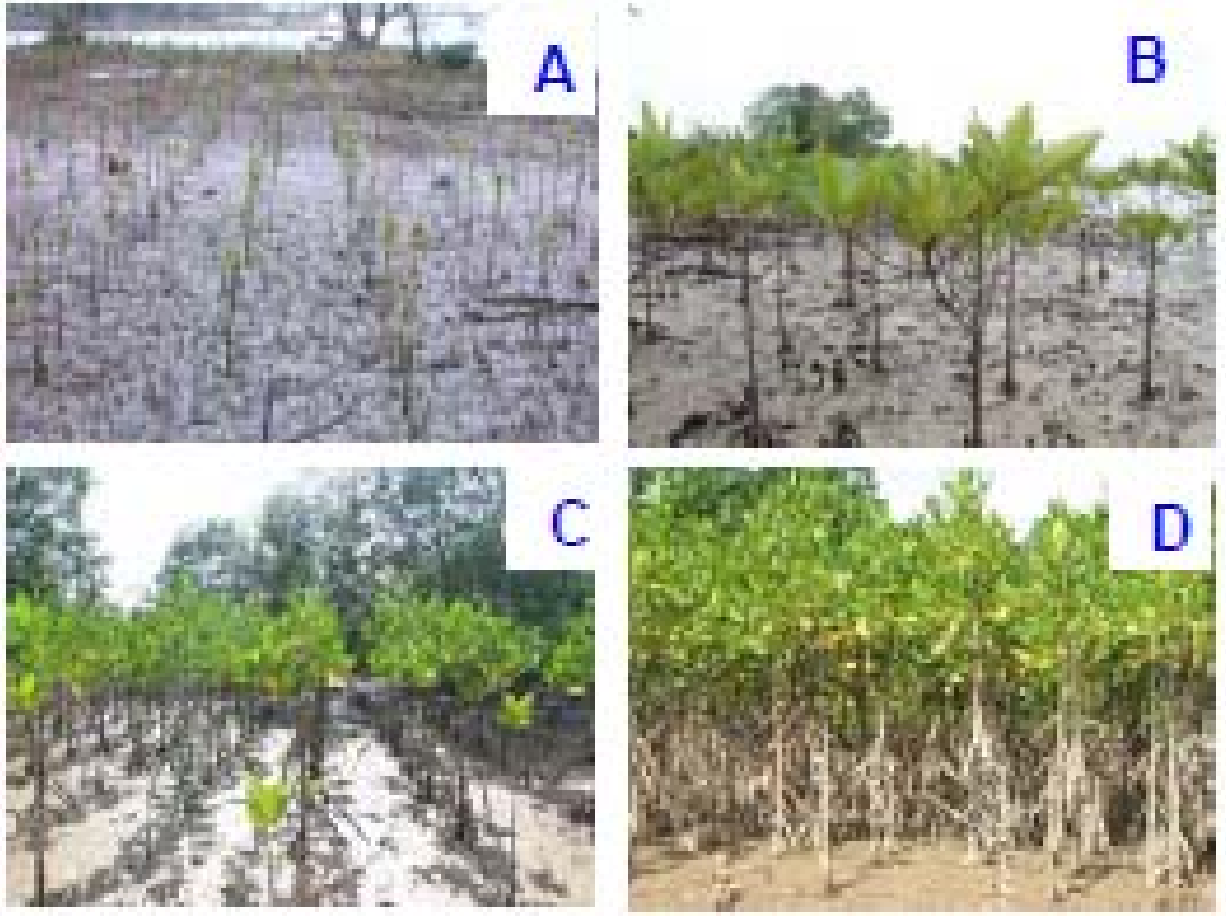

Fig. 7. Growth of replanted mangroves in the study area (courtesy of the Mangrove Resources Administration and Management Division No. 2, DMCR, MONRE).

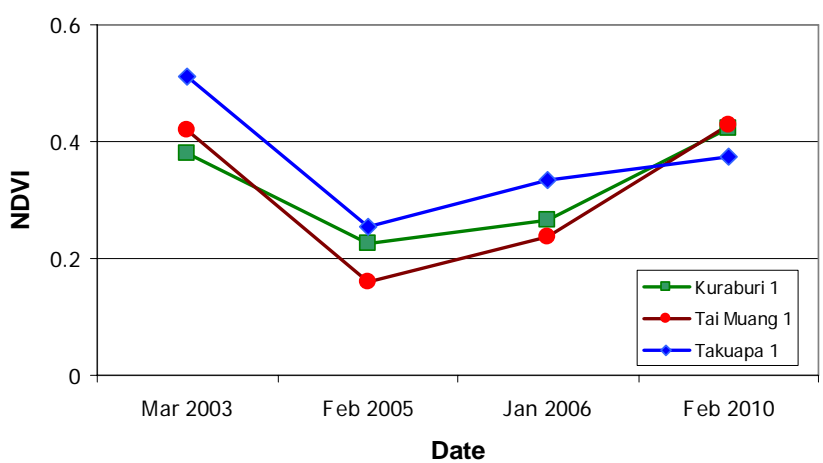

Fig. 8. NDVI fluctuation pattern of the gradually recovered mangrove areas (homogeneous plots).

A representative area in Takuapa demonstrating a fluctuating recovery is presented in Fig. 11.

As presented in Fig. 11, the area impacted by the tsunami shows less red and more blue than in 2003, representing a decrease in the mangrove cover. However, even after the new mangrove trees were replanted in the same location, the amount of red did not increase in 2006 because of the limited number of mangrove trees that survived. After the tsunami, the soil quality in this area was degraded because the tsunami removed the top layer of fertile soil, replacing the sandy subsoil with a layer of silt on the top.

The number of newly planted mangrove trees that survived in the study area was regularly monitored by the local DMCR staff. Moreover, dead and weak mangrove trees were replaced, resulting in increased NDVI values in 2010.

\section{Discussion and conclusions}

Because mitigation and protection against the 2004 Indian Ocean Tsunami was one of the important services that mangrove ecosystems had provided in the affected area, a sixyear program to conserve and rehabilitate mangrove forests in the tsunami-impacted areas was implemented by the Thai Government after the tsunami. However, information on mangrove restoration and reforestation is limited to field studies. This study therefore reviewed the application of geoinformatic technologies such as RS, GIS, and GPS as well as field surveys in studying changes in mangrove areas before and after the tsunami, and in assessing the recovery during the reforestation program to 2010 . In spite of the reforestation in 2005, the area classified as mangroves was reduced in 2006: the reforestation effort was unsatisfactory, as few trees survived in some locations where the topography had changed and the soil quality had deteriorated. Although 

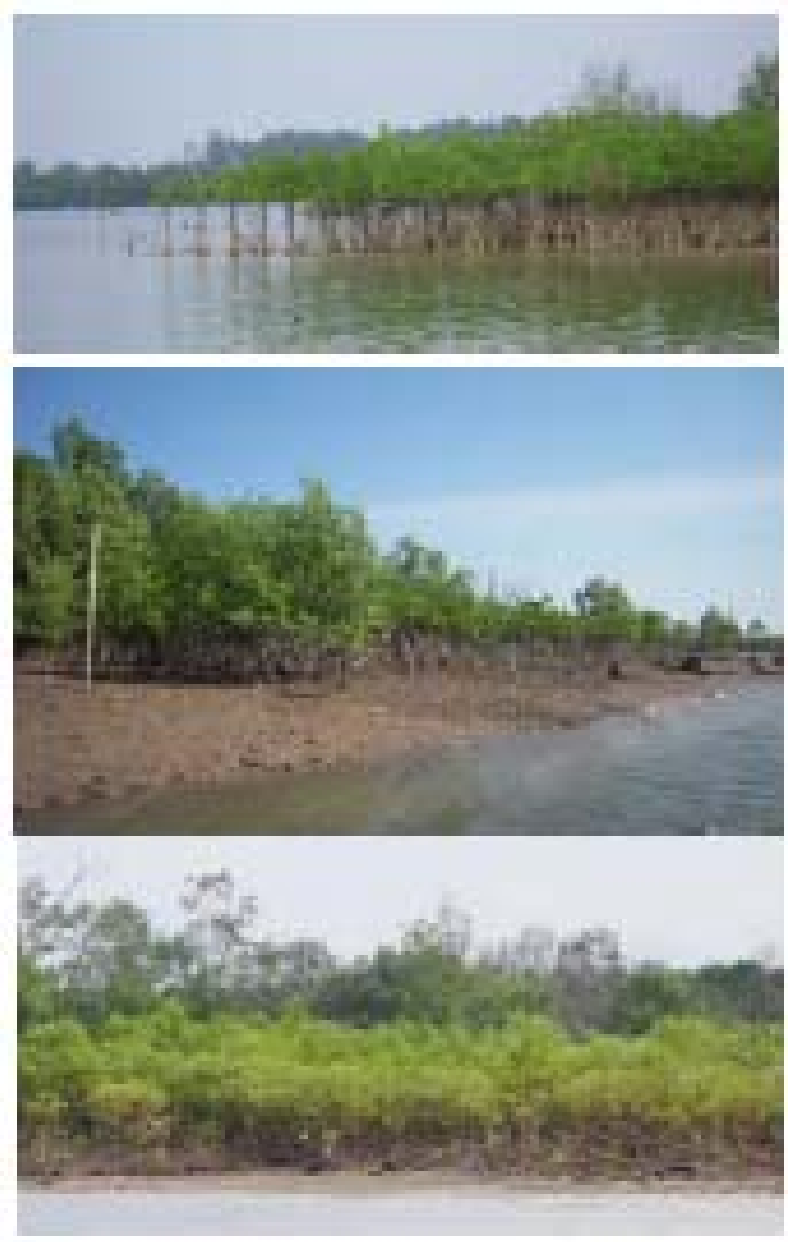

Fig. 9. Updated status of the gradually recovered mangrove areas (homogeneous plots).

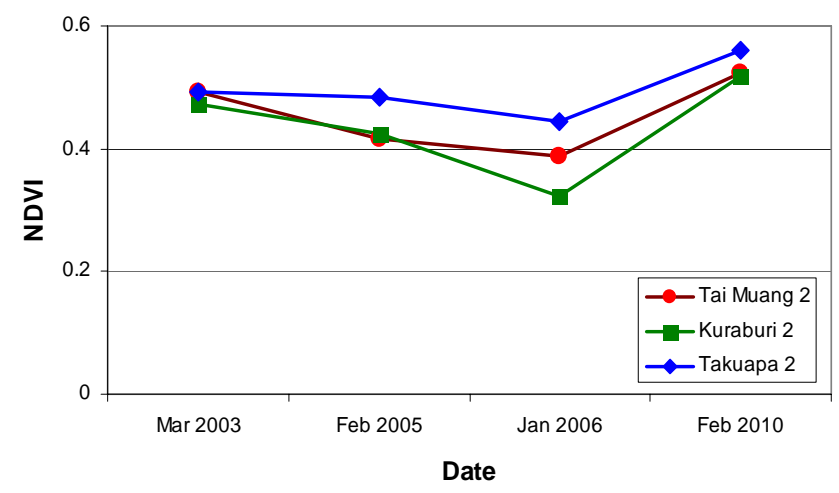

Fig. 10. NDVI fluctuation pattern of the mangroves that underwent fluctuating recovery (heterogeneous plots).
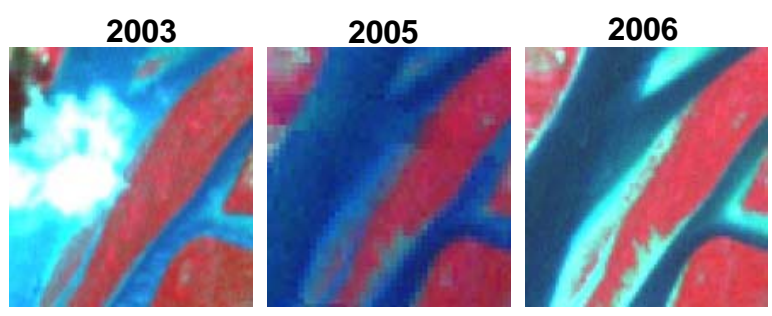

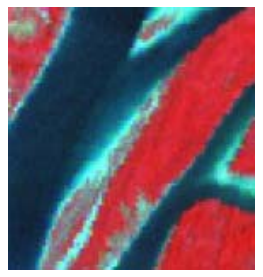

2010

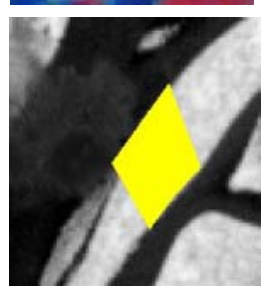

NDVI
Fig. 11. The fluctuating recovery of the mangrove area (heterogeneous plot) in Takuapa

the reforested area might have covered all the damaged mangrove areas with proper density, some areas might have been classified as other land cover types in the image (such as water body) where the number of trees was reduced in later years. After the tsunami, mangroves in the study area that were outside of the tsunami-impacted zone might have been converted into shrimp farms or dedicated to urban recovery and tourism-related development. Monitoring of the condition of the mangrove in the reforested areas is therefore crucial in understanding the progress of the recovery.

Because the multi-temporal NDVI presented a good picture for understanding the recovery patterns of the reforested mangrove areas, the patterns of NDVI were correlated with the field data and growth observations made by the local staff of DMCR. The patterns of recovery were then summarized based on damage levels, whether serious or partial. Moreover, the recovery patterns that implied to the patterns of replanting in the reforested plots (homogeneous or heterogeneous) were grouped into 2 categories, namely: (i) gradual recovery (homogeneous pattern), and (ii) fluctuating recovery (heterogeneous pattern). These results have enhanced the abilities of geoinformatic technologies, especially regarding the time series analysis. The results of this study will be very useful in supporting decision-making by policy makers or authorized officers of the Thai government in the development of appropriate mangrove rehabilitation plans. The results would also be useful for implementing mangrove resource management projects and establishing disaster prevention strategies. 

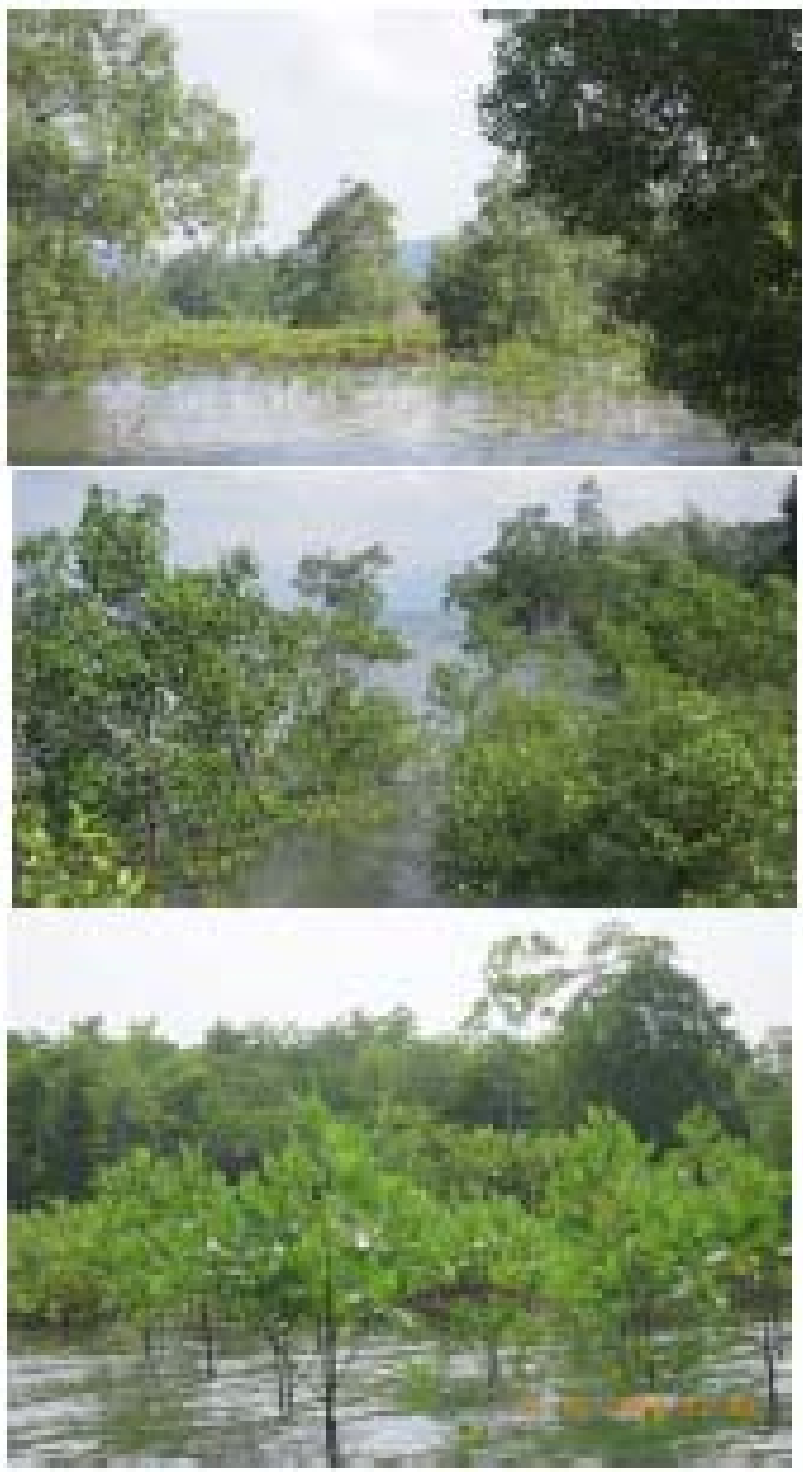

Fig. 12. The updated status of the mangrove that underwent fluctuating recovery (heterogeneous plots).

Acknowledgements. This study received financial support through project ID 08E52010a, which is hosted by Tohoku University and supported by the New Energy and Industrial Technology Development Organization (NEDO) of Japan, for which the author is very thankful. The author also appreciates the support of the GEO Grid and the National Institute of Advanced Industrial Science and Technology (AIST) in providing the ASTER data. The author also wishes to thank the local staff of the Mangrove Resources Administration and Management Division No. 2 of the DMCR, MONRE and the DDPM of the Ministry of Interior for compiling and supplying the field data, pictures, reports, and other help.

Edited by: R. Lasaponara

Reviewed by: three anonymous referees

\section{References}

Barbier, E. B.: In the wake of tsunami: Lessons learned from the household decision to replant mangroves in Thailand, Resour. Energy Econ., 30, 229-249, 2008.

Blasco, F., Gauquelin, T., Rasolofoharinoro, M., Denis, J., Aizpuru, M., and Caldairou, V.: Recent advances in mangrove studies using remote sensing data, Mar. Freshwater Res., 49, 287-296, 1998.

Chatenoux, B. and Peduzzi, P.: Impacts from the 2004 Indian Ocean Tsunami: analyzing the potential protecting role of environmental features, Nat. Hazards, 40-2, 289-304, 2007.

DMCR (Department of Marine and Coastal Resources): Rapid Assessment of the Tsunami Impact on Marine Resources in the Andaman Sea, Thailand, Phuket Marine Biological Center (PMBC), Phuket, Thailand, 76 pp., 2005.

DMCR (Department of Marine and Coastal Resources): The study on ecosystems and changes of coastal forests affected by the 2004 tsunami, Department of Marine and Coastal Resources, Ministry of natural Resources and Environment, Bangkok, Thailand, 86 pp., 2006.

Forbes, K. and Broadhead, J.: The role of coastal forests in the mitigation of tsunami impacts, FAO Report, Food and Agriculture Organization of the United Nations Regional Office for Asia and the Pacific Bangkok, 2007.

Jean-Baptiste, N. and Jensen, J. R.: Measurement of Mangrove Biophysical Characteristics in the Bocozelle Ecosystem in Haiti Using ASTER Multispectral Data, Geocarto International, 21, 4, 2006.

Jensen, J. R., Lin, H., Yang, X., Ramsey III, E., Davis, B. A., and Thoemke, C. W.: The measurement of mangrove characteristics in southwest Florida using spot multispectral data, Geocarto International, 6, 2, 13-21, 1991.

Kashio, M.: Tsunami impact assessment in mangrove and other coastal forests in the southern Thailand, FAO Report, FAO Regional Office for Asia and the Pacific, Bangkok, Thailand, 8 pp. (www.fao.org/forestry/8553-1-41.pdf), 2005.

Kathiresan, K. and Rajendran, N.: Coastal mangrove forests mitigated tsunami, Estuar. Coast. Shelf S., 65, 601-606, 2005.

Koshimura, S., Matsuoka, M., and Kayaba, S.: Tsunami hazard and structural damage inferred from the numerical model, aerial photos and SAR imageries, In: Proceedings of the 7th International Workshop on Remote Sensing for Post Disaster Response, 2009.

Kouchi, K. and Yamazaki, F.: Characteristics of Tsunami-Affected Areas in Moderate-Resolution Satellite Images, IEEE T. Geosci. Remote Sens., 45, 6, 2007.

ONEP (Office of Natural Resources and Environment Pollicy and Planing): 2 Years After Tsunami: Restoration of Thailand's Natural Resources and Environment. Ministry of Natural Resources and Environment, Bangkok, Thailand, 150 pp., 2006.

Polngam, S.: Remote sensing technology for Tsunami Disasters Along the Andaman Sea, Thailand, in Proceeding of the 3rd International Workshop on Remote Sensing for Post-Disaster Response 12-13 September 2005, Chiba, Japan, 2005.

Rodfai, C.: A Tsunami Impact on Mangrove and Beach Forest and the Recovery, Mangrove Resources Administration and Management Division No. 2, Office of Mangrove Resources Conservation, Department of Marine and Coastal Resources, Ministry of Natural Resources and Environment, 48 pp., 2005 (in Thai).

Rodfai, C.: Mangrove: Aftermath of the 2004 Tsunami to Present, 
Mangrove Resources Administration and Management Division No. 2, Office of Mangrove Resources Conservation, Department of Marine and Coastal Resources, Ministry of Natural Resources and Environment, 31 pp., 2008 (in Thai).

Roemer, H., Kaiser, G., Sterr, H., and Ludwig, R.: Using remote sensing to assess tsunami-induced impacts on coastal forest ecosystems at the Andaman Sea coast of Thailand, Nat. Hazards Earth Syst. Sci., 10, 729-745, doi:10.5194/nhess-10-729-2010, 2010.

Sirikulchayanon, P., Sun, W., and Oyana, T. J.: Assessing the impact of the 2004 tsunami on mangroves using remote sensing and GIS techniques, Internat. J. Remote Sens., 29, 12 June 2008, 3553-3576, 2008.

Siripong, A.: Andaman Seacoast of Thailand Field Survey after the December 2004 Indian Ocean Tsunami, Earthquake Spectra, 22, S3, S187-S202, 2006.

Tanaka, N.: Vegetation bioshields for tsunami mitigation: review of effectiveness, limitations, construction, and sustainable management, Landsc. Ecol. Eng., 5, 1, 71-79, 2009.

Thanawood, C., Yongchalermchai, C., and Densrisereekul, O.: Effect of the December 2004 Tsunami and Disaster Management in Southern Thailand, Science of Tsunami Hazards, 24, 3, 206, 2006.
Tsuji, Y., Namegaya, Y., Matsumoto, H., Iwasaki, S., Kanbua, W., Srivichai, M., and Meesuk, V.: The 2004 Indian tsunami in Thailand: Surveyed run-up heights and tide gauge records, Earth Planets Space, 58, 223-232, 2006.

UNEP (United Nations Environment Programme): After the Tsunami: Rapid Environmental Assessment, 140 pp., 2005

UNEP-WCMC: In the front line: shoreline protection and other ecosystem services from mangroves and coral reefs, UNEPWCMC, Cambridge, UK, 33 pp., 2006

Vu, T. T., Matsuoka, M., and Yamazaki, F.: Dual-scale Approach for Detection of Tsunami Affected Areas Using Optical Satellite Images, Internat. J. Remote Sens., 28, 2995-3011, 2007.

World Bank/UNDP: Tsunami Thailand: One Year Later: National Response and the Contribution of International Partners By the United Nations Country Team in Thailand, 122 pp., 2005.

Yamazaki, F., Matsuoka, M., Warnitchai, P., Polngam, S., and Ghosh, S.: Tsunami Reconnaissance Survey in Thailand Using Satellite Images and GPS, Asian J. Geoinformatics, 5, 2, 53-61, 2005. 